GASPARI, Elio. A ditadura envergonhada: as ilusões armadas. São Paulo: Companhia das Letras, 2002, 417 p; A ditadura escancarada: as ilusões armadas. São Paulo: Companhia das Letras, 2002, 507 p; e A ditadura derrotada: o sacerdote e o feiticeiro. São Paulo: Companhia das Letras, 2003, $538 \mathrm{p}$.

\title{
Uma análise sobre a trilogia de Elio Gaspari que trata da ditadura militar brasileira.
}

\author{
A major work with great gaps.
}

Waldir José Rampinelli ${ }^{1}$

O trabalho desenvolvido pelo jornalista Elio Gaspari² analisa um período importante da história do Brasil, já que medidas tomadas lá são sentidas amargamente ainda hoje. Uma delas foi a política de extermínio de grupos armados que se opuseram ao fim do Estado de direito; outra, o endividamento externo imposto ao país pelos banqueiros internacionais e o conseqüente aprofundamento do grau de dependência. Ambas, tratadas longamente nessa obra.

Quanto à estratégia para derrotar os oponentes, os generais-presidentes utilizaram a tortura e o terror estatal, descritos em detalhes pelo autor. No entanto, ele esquece de dizer que tais métodos visavam não apenas a destruir os opositores ideológicos, mas também preparar o caminho para uma acumulação capitalista internacional sem precedentes na história. A própria redemocratização, apoiada até pelo governo Ronald Reagan, buscou consolidar, dentro de um Estado de direito, o objetivo que a ditadura perseguia por meio da tortura: a transferência de nosso excedente econômico para o centro hegemônico de poder mundial. As duas últimas décadas ${ }^{3}$ de desenvolvimento capitalista na América Latina - afirmam Petras e Veltmeyer - configuraram um período de prosperidade jamais igualado para os bancos e as corporações multinacionais estadunidenses, bem como de um poder político quase incontestado exercido por Washington ${ }^{4}$.

No que toca ao crescimento da dívida externa, o autor faz uma análise da conjuntura internacional e de como os petrodólares foram encaminhados ao país. Porém, não comenta que toda essa operação foi possível graças à liquidação física, quando não moral, dos oponentes.

1. Jango: um provocador?

A Política Externa Independente (PEI), criada por Jânio Quadros e seguida por João Goulart, causava muitos problemas aos interesses estadunidenses, já que ela defendia a preservação da paz, por meio da prática da coexistência e do apoio ao desarmamento geral e progressivo; reafirmava o fortalecimento dos princípios de não-intervenção e autodeterminação dos povos; buscava a ampliação do mercado externo brasileiro mediante o desarmamento tarifário da América Latina e a intensificação das relações comerciais com todos os países, inclusive os socialistas; apoiava a emancipação dos territórios não-autônomos, fosse qual fosse a forma jurídica utilizada para a sua sujeição à metrópole; e tentava uma política de autoformulação dos planos de desenvolvimento econômico e de prestação e aceitação da ajuda internacional ${ }^{5}$.

\footnotetext{
${ }^{1}$ Professor do Departamento de História da Universidade Federal de Santa Catarina. Doutor em Ciências Sociais - Política pela Pontifícia Universidade Católica de São Paulo.

${ }^{2}$ Refiro-me aos livros A ditadura envergonhada: as ilusões armadas. São Paulo: Companhia das Letras, 2002, 417 p; A ditadura escancarada: as ilusões armadas. São Paulo: Companhia das Letras, 2002, 507 p; e A ditadura derrotada: o sacerdote e o feiticeiro. São Paulo: Companhia das Letras, 2003, 538 p.

${ }^{3}$ Os anos 1980 e 1990.

${ }^{4}$ PETRAS, James; VEITMEYER, Henry. Hegemonia dos Estados Unidos no novo milênio. Petrópolis: Vozes, 2000, p. 21.

${ }^{5}$ DANTAS, San Tiago. Política externa independente. Rio de Janeiro: Civilização Brasileira, 1962, p. 5.
} 
Esses princípios fizeram da PEI a mais avançada e a mais progressista política de toda a história do país. Tal política, mesmo quando sob a chancela de Afonso Arinos ${ }^{6}$, sofreu duras críticas do seu próprio partido, a União Democrática Nacional (UDN). Pedia-se, então, o regresso às normas do Itamaraty, para a política externa deixar de ser instrumento de decisões alheias; exigia-se cuidado com o avanço do comunismo, sendo os udenistas contrários a uma aproximação com a África e o Leste Europeu e favoráveis a uma intervenção militar em Cuba; enfim, solicitava-se o retorno a um alinhamento com os Estados Unidos ${ }^{7}$.

A PEI, embora o embaixador Lincoln Gordon afirmasse ser mais amistosa em relação a Washington que ao bloco socialista, deixou alguns governantes estadunidenses "alarmados por certa falta de flexibilidade das políticas brasileiras" ${ }^{8}$, o que foi, com certeza, uma das causas do apoio da Casa Branca ao golpe de Estado de 1964.

Uma vez deposto o presidente Goulart, o novo ministro das Relações Exteriores - Vasco Leitão da Cunha - rechaçou a PEI, invocando razões geopolíticas que vinculariam estreitamente o Brasil ao mundo ocidental e de modo especial aos Estados Unidos. Vasco Leitão declarou que o conceito básico da diplomacia brasileira passava a ser o da interdependência continental ${ }^{9}$.

Dois pronunciamentos oficiais marcam essa grande mudança na política externa brasileira: o primeiro foi um discurso de Vasco Leitão, em 19 de maio de 1965, saudando seu homólogo equatoriano, quando se referiu a "um conceito imanente à natureza da aliança interamericana, o da interdependência entre as decisões de política internacional dos países do continente"; o segundo pronunciamento, do próprio Castello Branco, ocorreu em 28 de maio de 1965, quando, referindo-se à invasão da República Dominicana por tropas estadunidenses com o apoio das brasileiras, defendeu a necessidade de substituir o conceito de fronteiras físicas por ideológicas ${ }^{10}$.

Castello Branco adotou uma política internacional intervencionista comandada pelos interesses do Departamento de Estado, substituindo o enfoque anatagonista Norte-Sul pelo conflito Leste-Oeste. A ruptura de relações diplomáticas com Cuba; o apoio à invasão da República Dominicana; o aplauso à decisão de Washington de encaminhar parte de sua ajuda militar à América Latina por meio da Organização dos Estados Americanos (OEA); a reivindicação de que se reativasse o dito "protocolo adicional", vinculando a ajuda militar à econômica; por fim, a defesa da tese da integração militar do continente com a criação de um exército interamericano permanente são políticas internacionais de Castello Branco em clara oposição ao governo de João Goulart ${ }^{11}$.

Elio Gaspari, na sua Ditadura envergonhada, não se refere em nenhum momento à Política Externa Independente quando analisa a queda de João Goulart, e tampouco à Política de Interdependência Continental ao falar da ascensão de Castello Branco ao poder. Sem dúvida, uma grande lacuna nessa grande obra.

\section{Quando começa a ditadura?}

O golpe de 1964 violentou o Estado de direito, e o Ato Institucional n. 5 (AI-5) foi apenas uma consequiência do seu aprofundamento. Considerar que a ditadura escancarada começou com a edição do AI-5, em 13 de dezembro de 1968, significa relativizar o período anterior que derrubou um presidente constitucional, desrespeitou as liberdades individuais e coletivas e submeteu o país aos interesses do capital internacional. Essa ditadura, inclusive, não estaria envergonhada, mas muito bem assumida. Daí que, se o exército dormiu janguista, acordou golpista e não

\footnotetext{
${ }^{6}$ Afonso Arinos de Mello Franco foi ministro das Relações Exteriores de 01/02/1961 a 10/09/1961. Exerceu novamente a função de 16/07/1962 a 17/09/1962.

${ }^{7}$ BENEVIDES, Maria Victoria de Mesquita. A UDN e o udenismo: ambigüidades do liberalismo brasileiro (1945-1965). Rio de Janeiro: Paz e Terra, 1981, p. 117.

${ }^{8}$ PARKER, Phyllis R. Brasil y la intervención silenciosa - 1964. México: Fundo de Cultura Econômica, 1984, p. 30.

${ }^{9}$ MARINI, Ruy Mauro. Subdesarrollo y revolución. 12 ed. México: Século XXI, 1985, p. 66-67.

${ }^{10}$ Ibidem, p. 68.

${ }^{11}$ Ibidem, p. 68.
} 
revolucionário. Portanto, o AI-5 não é o resultado do crescimento do terror de esquerda, mas sim da necessidade de institucionalização do terror de Estado.

A periodização da ditadura militar de segurança nacional, segundo Gaspari, é a seguinte: “de 1964 a 1967 o presidente Castello Branco procurou exercer uma ditadura temporária. De 1967 a 1968 o marechal Costa e Silva tentou governar dentro de um sistema constitucional, e de 1968 a 1974 o país esteve sob um regime escancaradamente ditatorial. De 1974 a 1979, debaixo da mesma ditadura, dela começou-se a sair. Em todas essas fases o melhor termômetro da situação foi a medida da prática da tortura pelo Estado"12.

Para Gaspari, embora todo o período seja denominado de ditadura, ele reforça o termo com a qualificação escancarada para os anos de 1968 a 1974 devido à intensificação do mecanismo da tortura. Com isso, ameniza o trabalho dos ditadores Castello Branco, Costa e Silva, Geisel e da junta militar. Se Médici foi quem mais baniu, exilou, torturou e matou, coube aos demais preparar as forças repressoras para atuar nos porões do regime e inocentá-las posteriormente. Por isso, não há mais ou menos ditador nessa longa noite sem luar de nossa história.

"A esquerda se arma, a direita se arma" - diz o autor -, como se uma guerra estivesse em marcha. Na realidade, são pequenos grupos com armas - e muito mal equipados - que enfrentam as forças armadas que chegaram ao poder e à Presidência por meio de um golpe de Estado. Não há uma guerra, já que não há dois Estados em litígio, muito menos dois exércitos em confronto. A falta de liberdade e a supressão dos elementos básicos da democracia burguesa levaram as pessoas a se organizarem clandestinamente na luta contra uma feroz ditadura, cujos pilares fundamentais estavam fincados no grande capital internacional ${ }^{13}$. Tampouco Cuba dispunha de tanto poder e tamanha influência, como quer fazer crer o autor dos livros, para ser responsabilizada pelas guerrilhas que atuavam no Brasil e na América Latina. Treinar pessoas, sim; ser responsável por tudo o que acontecia, não. "Pode-se divulgar idéias", dizia Fidel Castro, "mas não se pode exportar revoluções. As crises é que geram idéias e não as idéias que geram crises. Portanto, é uma prova de ignorância falar em exportar revolução"14.

Gaspari diz, em vários trechos, que a ditadura e o terrorismo de Estado originaram-se da anarquia militar. Penso que não, pois a matriz ideológica do regime foi a Escola Superior de Guerra (ESG), que por sua vez reproduzia no Brasil o pensamento de duas escolas estadunidenses: o National War College e o Industrial College of the Armed Forces. Enquanto a primeira estudava e aperfeiçoava a estratégia global dos Estados Unidos, com base na doutrina de segurança nacional, a segunda divulgava a sua respectiva teoria. A ESG do Rio de Janeiro foi um reflexo daquelas instituições de Washington, como fora também a Escola das Américas, do Panamá ${ }^{15}$. Portanto, nada de anarquia e tudo de planejamento.

\section{O "sacerdote" e o "feiticeiro": ambos macabros}

$\mathrm{O}$ autor das ditaduras envergonhada, escancarada e derrotada teve acesso direto aos arquivos pessoais do grande mentor intelectual do golpe de Estado de 1964: Golbery do Couto e Silva. No entanto, é preciso tomar muito cuidado com o documento, já que ele pode mostrar tão-somente um aspecto da história: o daquele que está no poder. As cartas, telegramas e memorandos do Ministério

\footnotetext{
${ }^{12}$ GASPARI, Elio. A ditadura enevergonhada...p. 129.

${ }^{13}$ Theotônio dos Santos e Vania Bambirra perguntam: "no interesse de que classes se concebe e se implanta a política da ditadura brasileira? Obvia e prioritariamente no interesse da grande burguesia monopolista nacional e estrangeira, isto é, das burguesias industrial, financeira e comercial integradas em uma unidade econômica nacional por meio de seus sócios maiores: o grande capital internacional". BAMBIRRA, Vania; DOS SANTOS, Theotônio. Brasil: nacionalismo, populismo y dictadura: 50 años de crisis social. In: GONZÁLEZ CASANOVA, Pablo (Org.). América Latina: história de medio siglo. 6. ed. México: Século XXI, 1986, p. 156.

${ }^{14}$ CASTRO, Fidel. Fidel e a religião: conversas com Frei Betto. 10 ed. São Paulo: Brasiliense, 1986, p. 355. Entrevista.

${ }^{15}$ COMBLIN, Joseph. A ideologia da segurança nacional. São Paulo: Civilização Brasileira, 1978.
} 
de Relações Exteriores, por exemplo, expressarão sempre a visão do governo. O pesquisador terá de fazer o documento falar, interrogando-o sistematicamente. "Não há pior conselho a dar a um iniciante" - afirma Marc Bloch - "do que [dizer para ele] esperar, numa atitude de aparente submissão, a inspiração do documento. Com isso, mais de uma investigação de boa vontade destinou-se ao fracasso ou à insignificância" 16 .

O sacerdote (Geisel) e o feiticeiro (Golbery) são apresentados como os desmontadores de uma longa ditadura militar, tendo para com eles uma atitude de simpatia, quando não de admiração, embora discordando de suas posturas em direitos humanos. $\mathrm{Na}$ verdade, ambos arquitetaram e executaram uma ditadura implacável para com seus opositores políticos, benevolente para com seus apoiadores empresários e toda submissa a seus mentores e admiradores capitalistas nacionais e internacionais. Tanto Geisel como Golbery se tornaram, em um dado momento, empregados de corporações multinacionais, não por suas qualidades técnicas, mas em recompensa por favores concedidos e pelas informações privilegiadas que traziam de seus cargos na República.

$\mathrm{O}$ sacerdote e o feiticeiro foram dois permanentes fora-da-lei. Não apenas trabalharam pelo fim do Estado de direito, golpeando um governo constitucional, como também apoiaram a criação de um ordenamento jurídico autoritário e espúrio. Dizer que um desmontou a ditadura e que o outro chegava às lágrimas quando ouvia relatos do martírio imposto a jovens estudantes é ser benévolo para com um regime autoritário que por mais de 20 anos desrespeitou os direitos fundamentais das pessoas, já proclamados no século 18 pela Revolução Francesa. Gaspari não apenas dedica um espaço desmedido a Geisel nessa sua obra, como também passa a idéia de o general-presidente ter sido um estadista pelo trabalho de desarticulação do regime.

Geisel, na verdade, foi um homem autoritário na caserna, para mais tarde tornar-se um presidente ditador na República. Conspirou contra vários mandatários eleitos, sempre dentro de uma perspectiva reacionária. Procurou eximir-se da responsabilidade da tortura exonerando o general Ednardo D'Ávila Mello do comando do II Exército, em São Paulo, não pelo desrespeito aos direitos fundamentais do homem e da mulher, mas sim pelos acidentes ocorridos com Manoel Fiel Filho e Vladimir Herzog. Vendeu a imagem de um soldado não envolvido com a política, mas dela se utilizou para dirigir o país autoritariamente. Mostrou ser um desenvolvimentista, sem quebrar os laços da dependência com o capitalismo internacional. Eurocêntrico, com críticas aos Estados Unidos, era preconceituoso em relação à índole do brasileiro.

Golbery trabalhou sempre nos bastidores do poder. Indicou muitos de seus companheiros da ESG para ocupar cargos importantes no governo. A res publica, com ele, tornou-se uma res privada, atendendo prestimosamente aos interesses do capital internacional. Seus representantes eram sempre bem-vindos ao Palácio do Planalto. Alguns deles, como Mr. Ludwig, do Projeto Jari, eram tão íntimos que entravam pela porta dos fundos. Arquitetou a criação de um partido político o Partido Trabalhista Brasileiro (PTB) - para apoiar a ditadura, com lideranças confiáveis e manipuláveis, em substituição aos nacionalistas-desenvolvimentistas. Trabalhou, como Salazar, o saber durar. Deixou o governo por discordar da condução da apuração do caso Riocentro. Na verdade, o aumento da luta dos povos em várias partes do mundo contra as ditaduras, como a ocorrida no Irã com a queda do Xá Reza Pahlevi; a pressão dos governos dos países centrais em favor de democracias burguesas, confiáveis e submissas; as sucessivas crises na economia com o fim de milagres econômicos; e a perda constante e sucessiva de legitimidade foram alguns dos fatores que ajudaram o velho golpista a abandonar o barco. Comparando as jogadas políticas com os movimentos de sístole e diástole do coração, viu que chegara o momento de entregar os anéis para não perder os dedos.

Agora, denominar esses dois senhores de "sacerdote" e "feiticeiro" é ser leniente com todo um período de arbítrio e de ruptura do Estado de direito.

\section{Algumas imprecisões}

${ }^{16}$ BLOCH, Marc. Apologia da história: ou o ofício do historiador. Rio de Janeiro: Zahar, 2001, p. 79 
1. O autor analisa o Brasil grande-potência do governo Médici, referindo-se à alegria trazida pela Copa do Mundo de 1970, bem como pela "temporada de patriotismo no ano do Sesquicentenário da Independência". Nesse contexto, "D. Pedro I regressaria ao Brasil, deixando a cripta do mosteiro dos Jerônimos, em Portugal, onde descansava desde 1834" "17. Na verdade, D. Pedro I - que em terras lusitanas leva o nome de D. Pedro IV - não estava nos Jerônimos, mas no mosteiro de São Vicente de Fora, em Lisboa. Na igreja dos Jerônimos estão somente os grandes nomes da história portuguesa, como Vasco da Gama, que achou o caminho para as Índias; a estátua de Luís de Camões, que descobriu o caminho para chegar a Portugal ${ }^{18}$; D. Sebastião e seu messianismo e outros. Já a família Orleans e Bragança, de somenos importância, tem seu panteão no São Vicente de Fora.

2. O autor, quando trata das relações políticas da ditadura brasileira com a portuguesa cita Angola, Moçambique, Guiné-Bissau e Cabo Verde como as colônias lusitanas existentes em março de $1974^{19}$. Esqueceu-se de outras três: as ilhas de São Tome e Príncipe, na África, Timor-Leste, na Oceania, e Macau, na Ásia.

3. Ainda sobre o colonialismo português, o autor diz que "todos os governos brasileiros apoiaram Portugal na sua guerra contra os africanos" 20 . A guerra colonial começou em novembro de 1961, com um grande massacre de angolanos, no norte do país. Jânio Quadros, com a sua PEI, já se distanciara do colonialismo português, no que fora seguido por João Goulart. O primeiro voto contra esse colonialismo se deu em 31 de julho de 1963, quando o Brasil, no Conselho de Segurança da ONU, disse sim a um projeto de resolução que convidava Portugal a reconhecer imediatamente o direito à autodeterminação e à independência de seus territórios ultramarinos ${ }^{21}$. Isso preocupou profundamente o governo português, tanto que Salazar ficou esperançoso quando do golpe de Estado de 1964, pois vislumbrava a instalação de um regime autoritário, anticomunista e de apoio à manutenção do império ultramarino português. Acertou nas duas primeiras previsões, não na terceira. Castello Branco não apoiou integralmente o colonialismo português e sugeriu "a formação gradual de uma Comunidade Afro-Luso-Brasileira, em que a presença brasileira fortificasse economicamente o sistema" 22 . A ditadura militar, de 1964 a 1974, não hostilizou Portugal, já que este era um aliado estratégico dos Estados Unidos no contexto da Guerra Fria ${ }^{23}$, mas se distanciou do apoio dado a Lisboa pelo governo Kubitschek (1956-1961). Adotou, então, com alguma ambigüidade, uma posição de abstenção. Portanto, é um equívoco dizer que "os governos brasileiros apoiaram Portugal na sua guerra contra os africanos".

A obra de Elio Gaspari - as ditaduras envergonhada, escancarada e derrotada - é muito importante para a historiografia brasileira, que tem se dedicado parcimoniosamente a esse período. O trabalho, muito mais de um jornalista do que de um historiador, embora tenha recebido muitos elogios, apresenta grandes lacunas e alguns equívocos.

${ }^{17}$ GASPARI, Elio. A ditadura derrotada... p. 189-190.

${ }^{18}$ SARAMAGO, José. Viagem a Portugal. 18 ed. Lisboa: Caminho, 1995, p. 291.

${ }^{19}$ GASPARI, Elio. A ditadura derrotada... p. 364.

${ }^{20}$ Ibidem, p. 365.

${ }^{21}$ MAGALHÃES, José Calvet de. Breve história das relações diplomáticas entre Brasil e Portugal. São Paulo: Paz e Terra, 1999, p. 106.

${ }^{22}$ Ministério das Relações Exteriores. A política exterior da revolução brasileira. 1966.

${ }^{23}$ Refiro-me à cedência dos Açores para a instalação de bases militares do Pentágono. Estas ilhas, diz Fernando Rosas, "são um elemento imprescindível para as tropas estadunidenses, sendo uma espécie de portaaviões no meio do Atlântico (e ainda hoje o são essencial para as manobras militares dos Estados Unidos)". ROSAS, Fernando. A Europa, os Estados Unidos e o Brasil de JK apoiaram a ditadura de Oliveira Salazar. Universidade e Sociedade, Brasília, ano xi, n. 26, 26 fev. 2002, p. 153. Entrevista concedida a Waldir José Rampinelli. 
Apenas duas curiosidades: o autor não falou da morte de Costa e Silva e demonstrou ter grande amizade com Golbery, Geisel e Heitor Ferreira, tornando-se o depositário de todo um acervo que, por certo, interessa ao país. Não deveriam esses documentos estar sob a guarda de um arquivo público para que todos tivessem acesso a eles? 